\section{$\underset{\substack{\text { hommes } \\ \text { \& migrations }}}{ }$}

\section{Hommes \& migrations}

Revue française de référence sur les dynamiques

migratoires

$1292 \mid 2011$

La discrimination au féminin pluriel

\title{
Laura Reeck, Writerly identities. In Beur fiction and
}

Beyond

USA, Lexington Books, 2011, 191 pages

\section{Mustapha Harzoune}

\section{(2) OpenEdition}

Journals

Édition électronique

URL : http://journals.openedition.org/hommesmigrations/660

DOI : 10.4000/hommesmigrations.660

ISSN : 2262-3353

Éditeur

Musée national de l'histoire de l'immigration

Édition imprimée

Date de publication : 1 juillet 2011

Pagination : 157-158

ISSN : 1142-852X

Référence électronique

Mustapha Harzoune, "Laura Reeck, Writerly identities. In Beur fiction and Beyond», Hommes \& migrations [En ligne], 1292 | 2011, mis en ligne le 29 mai 2013, consulté le 22 septembre 2020. URL: http://journals.openedition.org/hommesmigrations/660; DOI : https://doi.org/10.4000/

hommesmigrations. 660

Ce document a été généré automatiquement le 22 septembre 2020.

Tous droits réservés 


\title{
Laura Reeck, Writerly identities. In Beur fiction and Beyond
}

USA, Lexington Books, 2011, 191 pages

\author{
Mustapha Harzoune
}

\section{RÉFÉRENCE}

Laura Reeck, Writerly identities. In Beur fiction and Beyond, USA, Lexington Books, 2011, 191 pages

1 À l'heure où le pays s'apprête à vivre sous les fenêtres éclairées jusque tard dans la nuit des festivités célébrant le cinquantième anniversaire de l'indépendance algérienne et, au-delà, cinquante années de relations franco-algériennes, cette plongée dans l'univers romanesque d'auteurs français justement issus des immigrations algérienne et marocaine peut révéler bien des choses sur la société française et les attentes d'une partie importante de ses populations. L'intérêt ici est double. Il repose d'abord sur la finesse et la précision de l'analyse de chaque œuvre. Laura Reeck est professeure de français au College d'Allegheny aux USA et ce livre est le premier qu'elle consacre à quelques écrivains français que la République égalitaire et fraternelle relègue du côté des "beurs" ou des "écrivains de banlieue". À chacun - Azouz Begag, Farida Belghoul, Leilla Sebbar, Rachid Djaïdani, Mohamed Razane et Saïd Mohamed -, elle consacre un chapitre.

2 Autre intérêt, ces spécimens littéraires sélectionnés par Laura Reeck, pour converger ici ou là, présentent chacun un regard particulier et une expérience originale. La diversité des univers romanesques et des écrits traduit les processus sociaux, culturels, identitaires qui travaillent et taraudent la société, ses populations et ces auteurs. Ce n'est pas sans pertinence que Laura Reeck replace les œuvres dans leur contexte sociohistorique, depuis les rodéos de Vénissieux en 1980 jusqu'aux émeutes de 2005 en passant par la Marche de 1983. C'est dire si, ici, les questions identitaires ne se limitent pas à celles, mouvantes, des individus mais aussi à l'identité, tout aussi changeante, de 
la société française. Si, comme l'écrit Amin Maalouf, "l'intimité d'un peuple c'est sa littérature" (Le Dérèglement du monde, Le Livre de poche, 2010), alors avec ces nouveaux écrivains - français ! - on barbote au tréfonds des entrailles et de l'âme françaises.

Chez Azouz Begag, ci-devant ex-ministre, toujours chercheur en sociologie et écrivain devant l'éternel, l'identité s'émancipe dans un processus continu, individuel et déterritorialisé. La réussite ou l'échec de l'intégration n'est pas tant le fait d'un défaut de volonté des pauvres bougres aux cheveux noirs et bouclés que l'expression d'un rejet, d'un refus des hôtes, des "insiders". Sans la carte de membre du club, gare à l'exclusion, sournoise ou brutale. Au mieux, ces rejetons d'immigrés nord-africains servent de passeurs entre l'ici et le lointain, de "traducteurs" entre l'entre-soi propret et la mystérieuse cohorte des immigrés. "Traducteurs" mais non citoyens à part entière. Comme l'ont montré récemment Jean Mattern (Les Bains de Kiraly, Sabine Wespieser, 2008) et Stéphane Fière (Double bonheur, Métailié, 2011), les mots des autres forment un masque bien fragile et insatisfaisant pour qui aspire à une reconnaissance pleine et entière.

4 On peut, comme chez Farida Belghoul dans son unique roman, Georgette (B. Barrault, 1986), réduire l'orgueilleuse République et ses immigrés nouveaux à une société et à des minorités postcoloniales, et recourir aux notions de "fragmentation" et d'"exclusion réciproque" (Frantz Fanon) ou à celle d' "invisibilité" de Ralph Ellison. Exclu, invisible, l'imaginaire choisit de se cacher (ou de se réfugier) derrière un masque comme le petit Mehdi d'Une année chez les Français de Fouad Laroui (Julliard, 2010). Mais, pour affronter l'irrationnel et ici l'irrationnel est postcolonial, il faut en passer par la révolte silencieuse et par l'éducation (à l'image des personnages et de l'engagement de Farida Belghoul).

5 Leilla Sebbar proposerait des perspectives plus larges en termes d'études, et d'engagement. Analysée ici via les travaux de Kwam Anthony Appich et d'Edouard Glissant, la série des Shéhérazade présente un processus par lequel émerge un nouvel imaginaire. Un imaginaire qui bouleverserait les rapports entre le centre et les périphéries et où l'horizontalité des relations prendrait le pas sur la verticalité. Dans cette relation nouvelle (incarnée par Shéhérazade et Gilles), le droit à l'opacité se substituerait à la clarté des temps anciens, ceux où la lumière occidentale - et coloniale - écrasait les subtilités d'un monde bariolé, multicolore, et où la finitude entravait le cheminement, les processus de découverte, de connaissance, de métissage...

6 Michel Serres, Michel de Certeau, Salman Rushdie, Édouard Glissant, Le Clézio ou Mounsi servent à Laura Reeck pour décortiquer l'œuvre de Saïd Mohamed. Ce dernier incarne la figure du "poète maudit", celui qui refuse toute compromission, qui n'a que faire des thèmes à la mode, du marché et des plans médias des gourous-communicants de la politique ou de l'édition. Seul le style compte. Son champ est celui de l'autofiction. Pas le nombrilisme des petits bobos à l'âme des chouchous de la République. Ici l'autofiction serait "extravertie". Le "je" narratif est relié au monde. L'individu parle de lui à travers le monde, et le monde parle à travers l'individu. Les processus d'individuation sont complexes et l'individualité un bricolage qui n'a que faire du cadre étroit de la vérité.

7 Les mots chez Saïd Mohamed sont là pour restituer la parole des sans-voix : le père, la mère et la cohorte des sans-grade qui traverse ses récits. Et que constate-t-on? La diversité des voix, la restitution de l'Histoire par ses fantômes pour parler comme Michaël Ferrier, le lauréat 2011 du prix de la CNHI (Sympathie pour le fantôme, Gallimard, 
2010). En retournant au village paternel, il réintroduit le père dans l'Histoire, par ses propres mots - ceux de l'oralité - et son propre récit.

8 Avec Rachid Djaïdani et Mohamed Razane, on passe de la "littérature beur" aux écrivains de banlieue, ce qui serait une autre façon de "contenir", "séparer", "marginaliser", " exclure". Comme chez l'aînée Farida Belghoul, la multiculturalité à la française revient à "ghettoïser les différences", c'est dire si entre l'ânée et les jeunes auteurs des années deux mille il semble que pas grand-chose n'ait changé dans la société française, à tout le moins dans la perception que les principaux intéressés en ont.

9 Pourtant, depuis plus de trente ans, la même blessure taraude la plupart de ces auteurs : comment faire entendre qu'ils sont partie prenante de l'histoire et du devenir national, qu'ils partagent les valeurs héritées des Lumières et de la grande Révolution et qu'ils constituent une clef du futur de la société française ? Le titre du Manifeste "Qui fait la France ?" coécrit en 2007 par Razane résume ingénieusement cet engagement et cette déclaration de principe trentenaire : ils "kiffent" la France et participent à son dynamisme.

Qu'ils écrivent une "littérature engagée", une "autofiction extravertie" pour Saïd Mohammed, une "littérature au miroir" pour Razane ou une littérature "tout court" pour Djaïdani, tous mettent en avant la littérature, l'universalité de leurs propos, et la primauté du style et de la langue ! Le large spectre littéraire ici étudié (le premier livre est paru en 1986 et le dernier en 2007) permet de rendre compte des évolutions, des formes et des objets de ces engagements, avec pour toile de fond la capacité de la société française à se réinventer, à se régénérer dans le monde du $\mathrm{xxl}^{\mathrm{e}}$ siècle devenu le "Tout-Monde" d'Édouard Glissant. 